\title{
Risk factors of pancreatic cancer and their possible uses in diagnostics
}

\author{
Minireview
}

Jitka LANG ${ }^{1}$, Lumír KUNOVSKÝ ${ }^{2,3}$, Zdeněk KALA 3 , Jan TRNA ${ }^{1,2,4, *}$

${ }^{1}$ Department of Internal Medicine, Hospital Boskovice, Boskovice, Czech Republic; ${ }^{2}$ Department of Gastroenterology and Internal Medicine, University Hospital Brno, Faculty of Medicine, Masaryk University, Brno, Czech Republic; ${ }^{3}$ Department of Surgery, University Hospital Brno, Faculty of Medicine, Masaryk University, Brno, Czech Republic; ${ }^{4}$ Department of Gastroenterology and Digestive Endoscopy, Masaryk Memorial Cancer Institute Brno, Brno, Czech Republic

*Correspondence: jan.trna@seznam.cz

Received July 6, 2020 / Accepted November 12, 2020

\begin{abstract}
Pancreatic cancer (PC) is a form of malignancy of increasing incidence and poor prognosis, with an average of less than $10 \%$ of patients surviving 5 years after being diagnosed. The main reason for this unfavorable situation is the long asymptomatic course of the disease, and the absence of a simple screening method, typically leading to the late discovery of the disease. The development of the malignancy from the initial carcinogenesis into invasive pancreatic carcinoma takes approximately 10 years. However, the progression of pancreatic cancer from early into advanced stages can be, according to the latest studies, incredibly fast, just a few months. Early stages of pancreatic malignancy can be detected only by expensive, and sometimes invasive, diagnostic methods (CT, MRI, or EUS). Due to the current absence of a reliable non-invasive screening method, it is necessary to define a group of patients who have the highest risk of PC development, five to ten times higher risk compared to the regular population at a minimum. Risk factors combine in their effect; therefore, relative risks of PC development need to be summarized to obtain a total relative risk for each person. The main and non-influenceable risk factor in the development of PC is the increasing age. The other non-influenceable risk factor of PC is a genetic predisposition - family incidence of the disease can be detected in $4-16 \%$ of patients. Some specific genes and mutations, which can play a role in PC development have already been identified (for example mutation of the PRSS-1 gene). Among the influenceable risk factors of PC is primarily smoking; obesity can play a part in PC development as well. A higher risk of PC is observed in patients with chronic pancreatitis. Nowadays, the relationship between PC and diabetes mellitus (DM) is hotly discussed. In the case of long-standing DM, the risk of pancreatic cancer is two times higher compared to the healthy population. However, new-onset DM can be the first sign of still asymptomatic PC. These patients, with paraneoplastic DM caused by pancreatic cancer cells, represent approximately $1 \%$ of recently diagnosed patients. However, this group of patients is still too large for screening. Because of that, it is necessary to find specific criteria to distinguish classic DM from the paraneoplastic form. The application of these criteria can help with the better stratification of risk in patients with new-onset diabetes and hence, it can help to discover PC in its early stages.
\end{abstract}

Key words: pancreatic cancer, pancreatic ductal adenocarcinoma, risk factors, chronic pancreatitis, PanIN lesions, mucinous cystic neoplasm, diabetes mellitus, smoking

Pancreatic ductal adenocarcinoma (PDAC), accounting for approximately $90 \%$ of pancreatic malignancies, is a therapy-resistant tumor, with a gradually increasing incidence and still poor prognosis with a median five-year survival rate still below $10 \%$ [1]. According to the data of the National Cancer Registry of the Czech Republic, there was a gradual significant increase in both the incidence of pancreatic cancer (PC) and its mortality from 1994 to 2016 [https:// www.svod.cz/analyse.php?modul=incmor\#]. An unfavorable prognosis is associated with the long asymptomatic course of the disease, as a result of which the diagnosis is mostly late and most cases of PC are detected in the locally advanced stage, or even with already present distant metastases $[1,2]$.

PC oncogenesis is a multi-stage and relatively long process, occurring either by the gradual progression of the severity of changes in relatively rare mucinous cystic lesions 
(IPMN - intraductal papillary mucinous neoplasia and MCN - mucinous cystic neoplasia) or more often by the progression of the normal duct epithelium through the spectrum of pancreatic intraepithelial neoplasia (PanIN) into invasive PC $[3,4]$. See Figure 1 for a summary of these pathways.

Progression from normal ductal epithelium through mild and severe dysplasia is characterized by a sequence of genetic alterations involving primarily a mutation in the KRAS

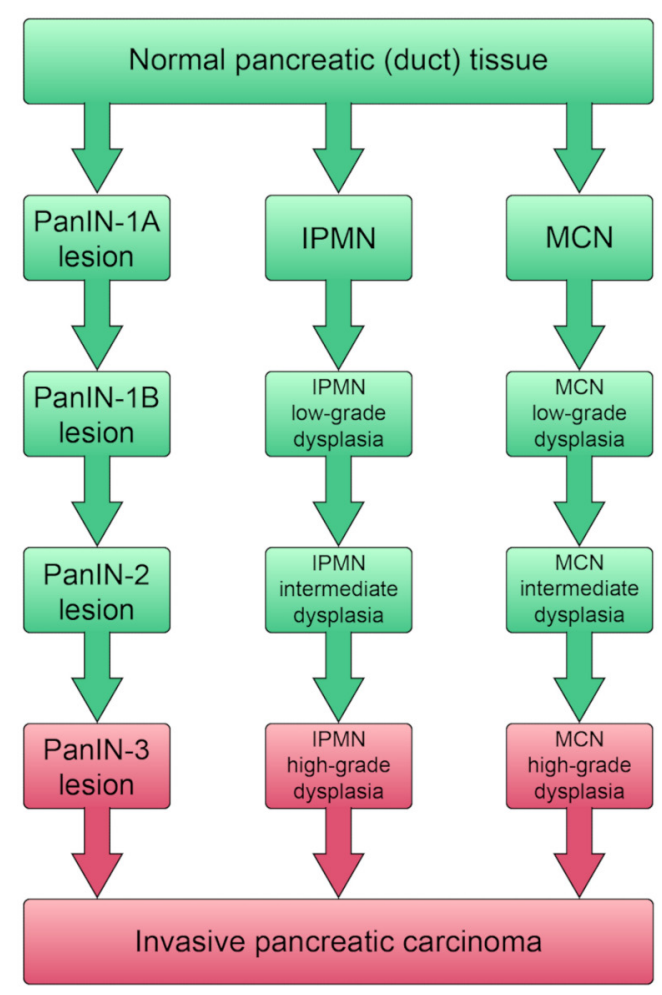

Figure 1. Three distinct pathological pathways to invasive pancreatic carcinoma (edited according to [4] - created in collaboration with Service Center for E-Learning at Masaryk University, Faculty of Informatics). oncogene, occurring in the early stages of PC oncogenesis. In the later stages of oncogenesis, mutations in the tumor suppressor genes TP53, CDKN2A, and SMAD4 (which are common in aggressive high-grade dysplasia) are typical [5]. See Figure 2 for details.

Overall, a development of about 10 years to the stage of invasive cancer is assumed, which on a theoretical level represents a sufficient time for early diagnosis $[4,6,7]$. However, there are alternative theories describing the possibility of significantly faster progress [8]. These accelerated genetic and epigenetic changes may explain the clinically known phenomenon of very rapid progression from localized PC to the advanced stages in months (Figure 3 and Figure 4) [9]. According to these theories, development may not be linear as expected according to the gradualism model, but due to the presence of factors such as aneuploidy, chromosomal instability, and chromothripsis (detectable in up to $60 \%$ of PCs), very rapid progression can occur, as predicted by punctuated equilibrium theory (Figure 5) [10].

\section{Screening and diagnostics of PC}

Theoretical background of PC screening. For the above reasons, it is necessary to search for people with early stages of PC to improve the PC prognosis. Due to its long asymptomatic course, it is necessary to search for asymptomatic individuals-conduct screening. Despite the increase in the incidence of PC, population screening cannot be considered justified, both for financial reasons and also for generating unacceptably high numbers of false-positive results $[11,12]$. For these reasons, research is currently focusing on efforts to identify and subsequently screen high-risk groups of people using our knowledge of risk factors for PC [13]. At least a 5-10-fold increase in PC risk is considered appropriate.

The defined group of people should have an expected risk of about $4 \%$ of finding PC in the following 3 years (Figure 6) [14]. Thus, medium- and high-risk groups can be considered

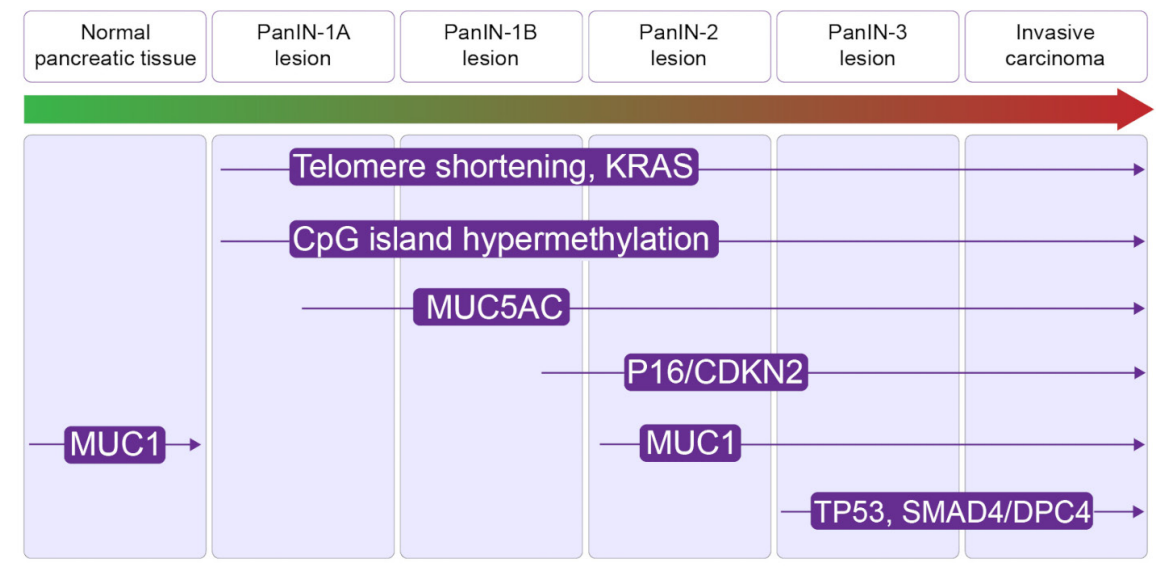

Figure 2. Molecular changes during the progression of normal pancreatic tissue through the spectrum of PanIN lesions into invasive PC (edited according to [4] - created in collaboration with Service Center for E-Learning at Masaryk University, Faculty of Informatics). 
suitable for screening, including some genetic mutations that cause, for example, hereditary chronic pancreatitis [15, 16 ] and a number of other tumor syndromes (Peutz-Jeghers syndrome, hereditary non-polyposis colorectal cancer (HNPCC), familial adenomatous polyposis (FAP), familial atypical multiple mole melanoma syndrome (FAMMM syndrome)) [17-20]. Risk groups also include persons with familial PC, which is defined as the occurrence of PC in at least two or more first-degree relatives $[21,22]$. In some meta-analyzes, the presence of Helicobacter pylori appears to slightly increase the risk of developing PC $[23,24]$. The individual risk factors, including the degree of increase in the risk of PC development, are summarized in Table 1 (adjusted according to $[11,13,17,18])$.

As a summary, it is possible to say that about $90 \%$ of PC is sporadic (associated with potentially modifiable risk factors), but in some individuals, PC can be attributed to familial aggregation (7\%) or high-risk genetic syndromes (3\%). Separate risk factors aggregate (maybe even multiply) in their effects and, therefore, it is necessary to determine the profile of risk factors for each individual and screen the ones with a substantial increase. In some groups, PC screening programs using imaging methods are already ongoing worldwide, however, the results of screening among patients from high-risk groups are not unambiguous. Professor Canto's group, which has been working on this issue for a long time, published the results of a long-term follow-up (16 years, median 5.6 years) of a group of 354 patients at high risk of PC using advanced imaging methods (EUS, MRI, CT). During the follow-up period, a suspected lesion was detected in 68 patients (19\%), and in 24 (7\%) there was a gradual progression. 9/10 of the detected PCs were resectable with a 3-year survival of $85 \%$ [25]. In contrast, a meta-analysis of examination studies (EUS or MRI) of high-risk ( $\geq 5 \%)$ PC patients, including 19 studies with a total of 7,085 patients, detected 59 high-risk lesions (43 PCs). Thus, it was necessary to examine 135 high-risk patients to detect one PC, and the authors question the cost-effectiveness of this approach [26].

Imaging methods. Due to the current absence of reliable laboratory markers, current diagnostics, including screening, is based primarily on the use of imaging methods.

The practical and sensitive imaging methods capable of accurate imaging of a pancreatic lesion and determining its
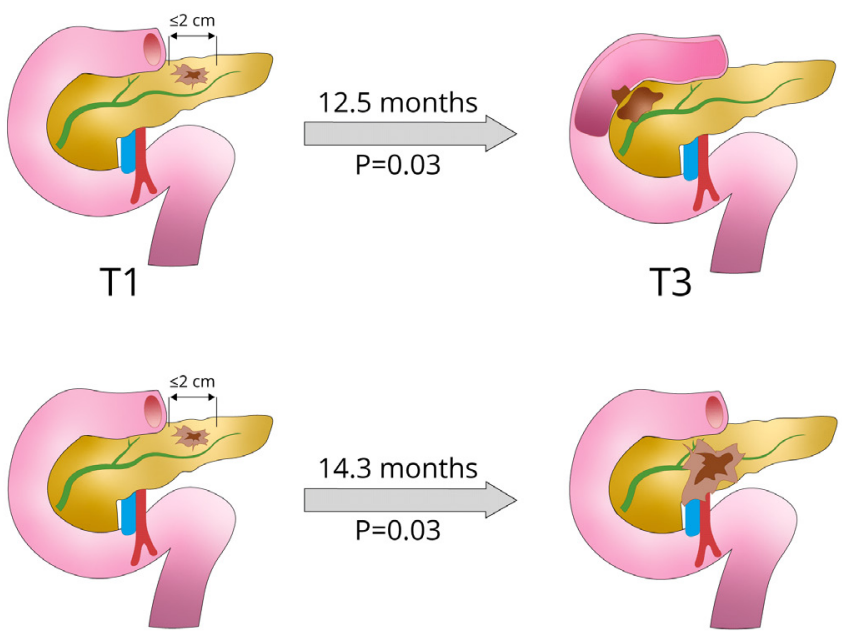

$\mathrm{T} 1$

T3

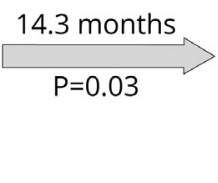

(average adjusted age difference)

Figure 3. Time progression of PC - a fast progression from PC stage T1 into $\mathrm{T} 3$ and $\mathrm{T} 4$ in 12.5 and $\mathbf{1 4 . 3}$ months respectively (edited according to [9] - created in collaboration with Service Center for E-Learning at Masaryk University, Faculty of Informatics).

stage are quality CT using a pancreatic protocol, MRI, EUS with the possibility of performing a fine-needle aspiration biopsy (FNAB) $[2,27]$.

Abdominal ultrasound (US) is the best initial modality for its minimal invasivity, common availability, and safety, however, due to the position of the pancreas in the retroperitoneum, abdominal ultrasound is not accurate enough in imaging of the pancreas.

On the contrary, endoscopic ultrasound (EUS) is a sensitive method for the identification of small lesions of the pancreas, which can be subsequently focused by fine-needle aspiration biopsy (FNAB). EUS is more sensitive than CT, especially for small lesions $(\leq 2 \mathrm{~cm})$ and it is also most reliable in the evaluation of infiltration of large visceral vessels and lymph node involvement [28].

However, EUS represents endoscopic = invasive procedure with relatively low availability and high operator dependence. Therefore, quality computed tomography (CT) using
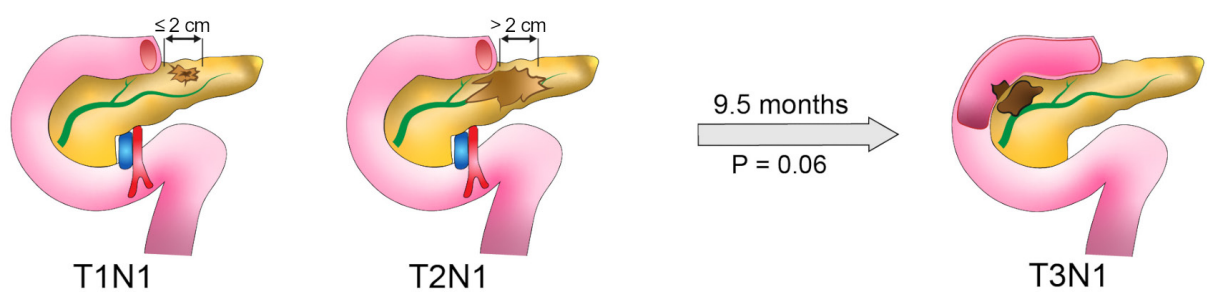

Figure 4. Time progression of PC - a fast progression from PC stage T1-2N1 into T3-N1 in 9.5 months (edited according to [9] - created in collaboration with Service Center for E-Learning at Masaryk University, Faculty of Informatics). 

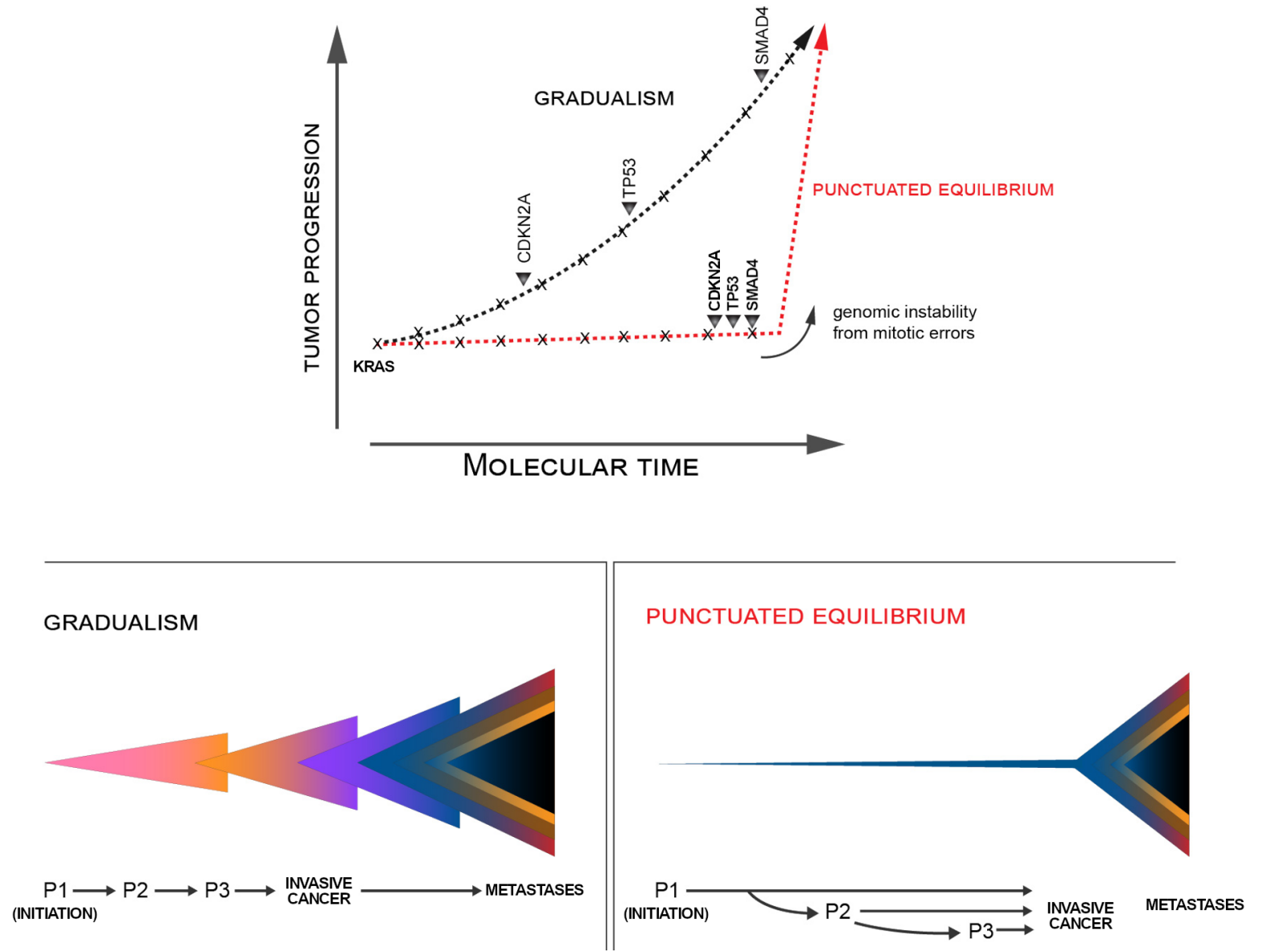

Figure 5. Different patterns of tumor progression in gradualistic and punctuated equilibrium models of pancreatic cancer progression (edited according to $[10]$ - created in collaboration with Service Center for E-Learning at Masaryk University, Faculty of Informatics).

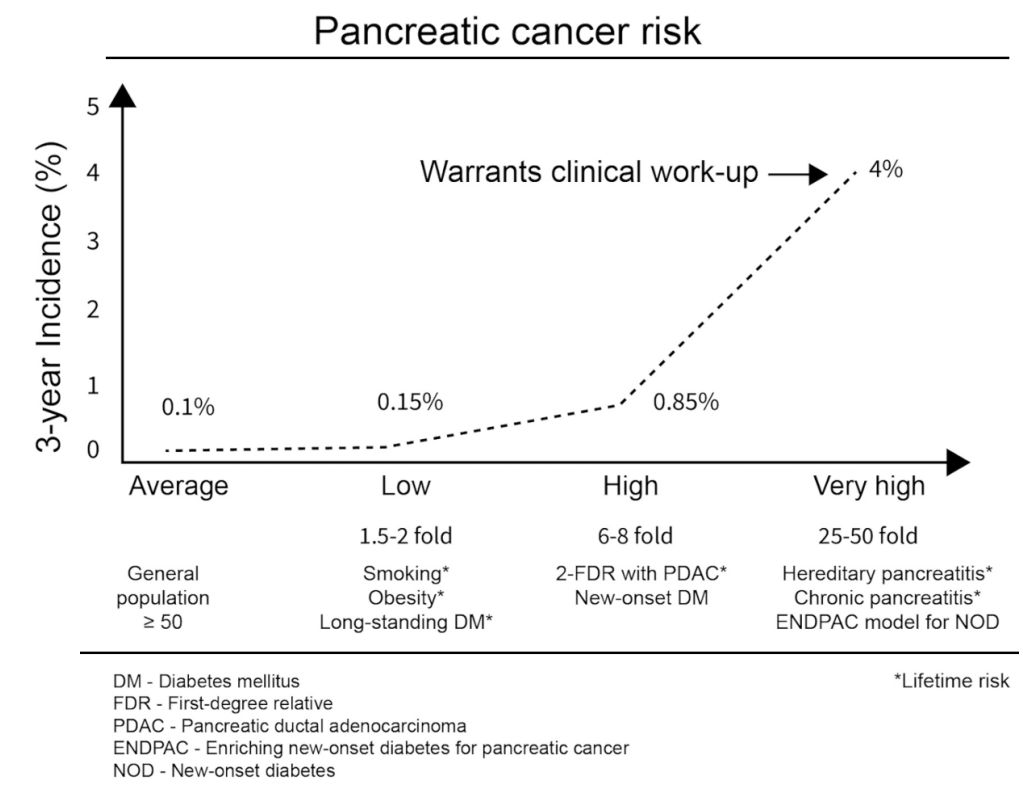

Figure 6. Increasing risk of pancreatic cancer in the presence of currently known risk factors (edited according to [14] - created in collaboration with Service Center for E-Learning at Masaryk University, Faculty of Informatics). 
pancreatic protocol (= triphasic scan in arterial, late arterial, and venous phases) is a fairly accurate and widely available modality with relatively high sensitivity and specificity for PC detection, which is also useful for distinction of patients eligible for resection with curative intent and those with the unresectable disease [29]. The limitation of CT is the ionizing radiation and the application of intravenous contrast, which is problematic in patients with renal failure or allergy.

In such cases, magnetic resonance imaging (MRI) with gadolinium infusion is an alternative method that can be used to diagnose and stage PC. MRI has not been proven to perform better than CT in PC detection while it is more expensive and less available [30]. The length and loudness of the procedure and the small gantry of the MRI scanner can be limiting for claustrophobic patients. Conversely, because of the absence of radiation, MRI is preferably used for screening of high-risk individuals when the need for repeated examinations can be expected.

The addition of positron emission tomography (PET) either to CT or MRI combines functional PET imaging with anatomical images of CT/MRI. Unfortunately, it does not differentiate inflammatory and malignant changes because both conditions manifest with increased accumulation of the tracer and therefore, PET does not differentiate PC from chronic pancreatitis. As such, PET-CT is similar to CT alone and does not bring much of further benefits except selected cases - detection of small distant metastases, monitoring of cancer recurrence after chemotherapy. PET-MRI seems to be more reliable than a PET-CT and may be useful in cystic tumors, where PET-MRI enables exact detection of structures located inside of the lesions, such as mural nodules or intracystic septa [31]. The overview of the diagnostic work-up of suspected pancreatic mass is summarized in Figure 7 [32].

In general, a major disadvantage of imaging methods in screening is the cost (CT, EUS, MRI), potential discomfort for the patient (EUS, MRI), and possibly a high rate of falsepositive examinations. Therefore, further improvement is necessary in the detection of significant precursors or early $\mathrm{PC}$ and also in better distinction from clinically nonsignificant lesions to avoid unnecessary surgery and psychological stress in false-positive cases. Thus, the most sensitive and cost-effective imaging screening protocol still needs to be defined. MRI seems more cost-effective in overall screening, with EUS more cost-effective for highest-risk individuals (relative risk >20). But cost-effectiveness depends on MRI and EUS costs that vary considerably among countries [33].

Laboratory diagnostics. Due to the cost and possible invasiveness of the above-mentioned imaging methods, a very attractive area of research is the effort to find a laboratory marker enabling a non-invasive PC screening in order to

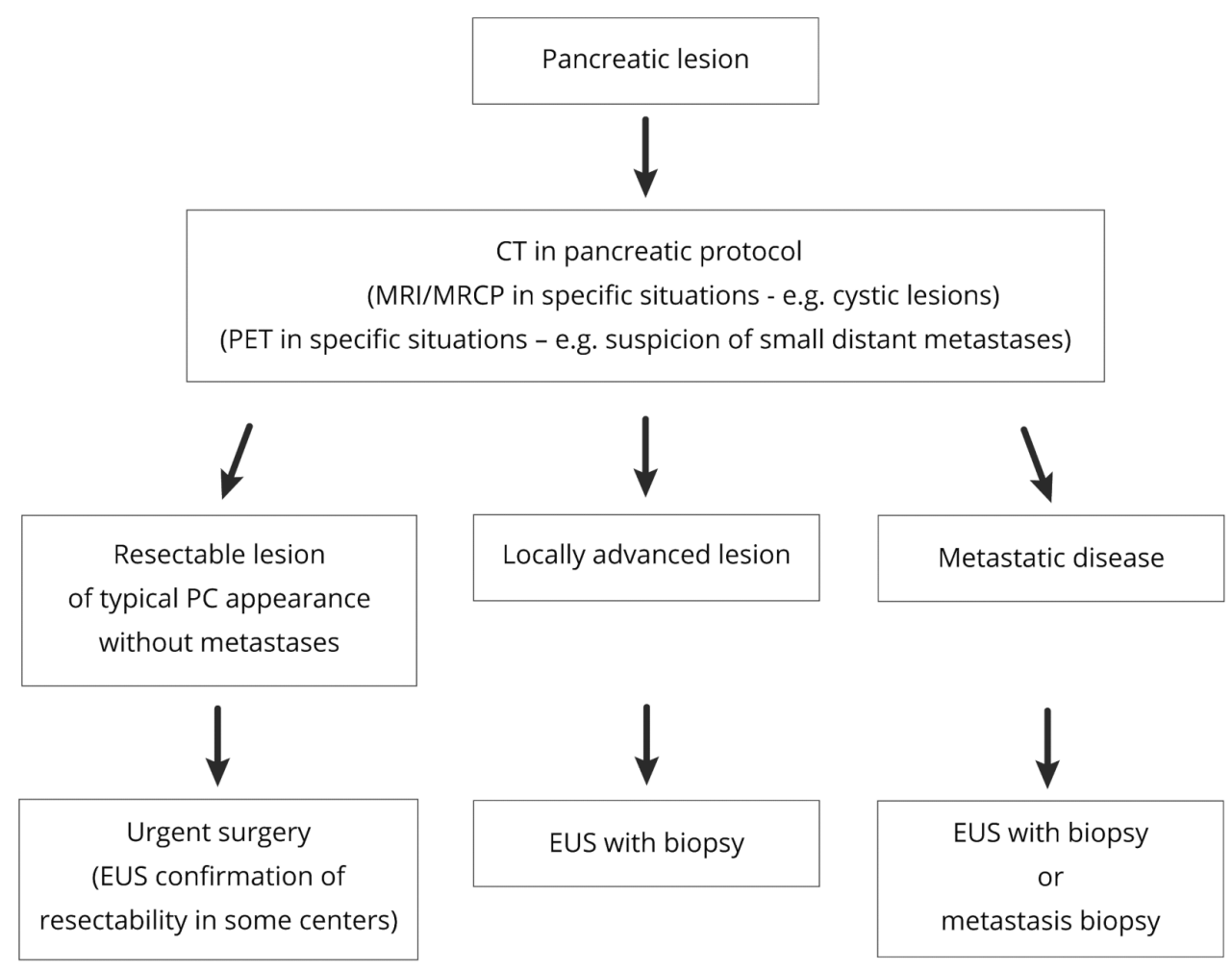

Figure 7. Diagnostic work-up of a suspected pancreatic mass (according to [32] - created in collaboration with Service Center for E-Learning at Masaryk University, Faculty of Informatics). 
capture the early stage of PC. Unfortunately, despite intensive research, no progress has yet been made that would allow the use in everyday clinical practice. Increased levels of the tumor marker carbohydrate antigen 19-9 (CA 19-9), which is currently the only one used in routine clinical practice, is usually associated with the advanced disease and a poor prognosis [34]. Also, in patients without a functional Lewis enzyme (7-10\% of the population), levels of CA 19-9 are typically undetectable or below $1.0 \mathrm{U} / \mathrm{ml}$. In addition, CA 19-9 positivity can be caused by a number of other (even benign) diseases including cholestasis [35]. Its role in the detection of the early stages is therefore limited and, thus, CA 19-9 is not recommended as a screening marker for PC [36].

A number of other potential markers have been and are being investigated, unfortunately, their real use in clinical practice has not yet been achieved [37]. However, some markers (e.g. MUC1, PC-594) show better results than CA $19-9$ in pilot studies $[38,39]$.

Immunoglobulin G4 (IgG4), which is considered the diagnostic marker of autoimmune pancreatitis (AIP), can be slightly increased also in patients with PC [40]. More than a two-fold increase in IgG4 levels should be considered specific for AIP, which in a combination with negative CA 19-9 makes a diagnosis of PC highly unlikely [41].

Promising results in PC diagnostics have been published using the methods of proteomics, genomics, metabolomics, and so-called "liquid biopsy" [42-44]. Currently, the use of a combination of new markers with CA 19-9 [45] and the use of panels of individual biomarkers [46] seem to be useful.

Liquid biopsy is detection of either circulating tumor cells (CTCs) or circulating tumor DNA (ctDNA) or tumor exosomes. They are either whole cells or their particles, derived from a primary tumor that have entered the vasculature and circulate within the bloodstream. CTCs possess the capability to seed in distant organs = to metastasize. The possible role of their detection in the early diagnosis of PC is in theory very promising. The identification and isolation of CTCs, ctDNA, and/or tumor exosomes in PC is quite difficult, not standardized, with limited consistency of the results, however, studies have shown their presence in the bloodstream in the early stages of PC [47]. Thus, methods of liquid biopsy represent a promising path for the early detection of PC especially as profiling of several individual markers. Findings also suggest that higher diagnostic values of liquid biopsy methods available today can be reached when analyzed in a combination with CA19-9. A standardized detection method and large-scale validation are required before a wide clinical application.

In summary, while it is hard to predict future development in the field, methods of liquid biopsy (especially miRNAs), proteomics, metabolomics appear the most promising. The near future probably lies in a carefully selected panel of biomarkers that would allow for earlier diagnosis of PC and easier determination of its stage and, ideally, also for tailoring of the treatment plan and indication of prognosis/outcome.
Screening-summary and implications for clinical practice. The primary goal of PC surveillance should be the prevention of $\mathrm{PC}$ related death and prevention of $\mathrm{PC}$ emergence by identifying and treating its precursor lesions. The average lifetime risk of developing PC in the general population is too low for population-based screening. Therefore, high-risk groups of patients need to be identified by taking into account present risk factors (their total in case of more risk factors). Individuals with $\mathrm{PC}$ risk increased $\geq 5$ times may be screened for PC.

Currently, patients with familial PC and hereditary pancreatic cancer syndromes caused by certain germline mutations are considered candidates for PC screening. In the future, individuals with a substantial increase in PC based on modifiable risk factors may be subjects to PC screening programs as well.

Careful physical examination, family and personal history including information on smoking, dietary habits, and exposure to toxins can be helpful in the identification of individuals eligible for PC screening. Furthermore, obtaining a comprehensive cancer family history from newly diagnosed PC patients can help to identify family members who may benefit from the surveillance.

At the present, EUS and MRI represent the most sensitive imaging methods used in PC diagnostics and they are the cornerstones of PC screening programs. However, the most sensitive and cost-effective imaging screening protocol still needs to be defined.

Unfortunately, laboratory tests available today are not capable of reliable early diagnostics of PC but, in the future, we can expect rapid development of laboratory tests using the methods of proteomics, genomics, metabolomics, and so-called "liquid biopsy" [42, 44]. This may even allow population screening of $\mathrm{PC}$ in the general population.

The overview of the recommended approach to initial screening and further follow-up of persons with germline mutations with increased risk of PC development is summarized in Figure 8 [20]. This approach may be in the future applicable also for people with a substantially increased risk of PC based on the age and accumulation of environmental risk factors. Some national guidelines recommend for highrisk individuals even earlier start of the PC screening (at age of 35) with annual EUS and serum CA19-9 [48].

\section{Individual risk factors}

Risk factors of PC development can be divided into non-modifiable and modifiable risk factors. Non-modifiable risk factors are represented primarily by the age and genetics of each individual, modifiable risk factors mostly by lifestyle factors such as smoking, diet, and toxins. Certain risk factors, such as obesity, diabetes, and CP, might be in part modifiable indirectly by a life-long healthy lifestyle, but they are difficult to influence once present. The risk factors are summarized in Table 1. 
Familial PC, Peutz-Jeghers syndrome (STK11 mutation)

Initial surveillance starts at 50-55 or 10 years younger than the youngest affected blood relative (some sources recommend 30-35 for Peutz-Jeghers syndrome)

\section{Germline mutations in: PRSS-1, BRCA1+2, ATM, CDKN2A, PALB2, $M S H 1+2, T P 53$}

Initial surveillance starts at $40-50$ or 10 years younger than the youngest affected blood relative

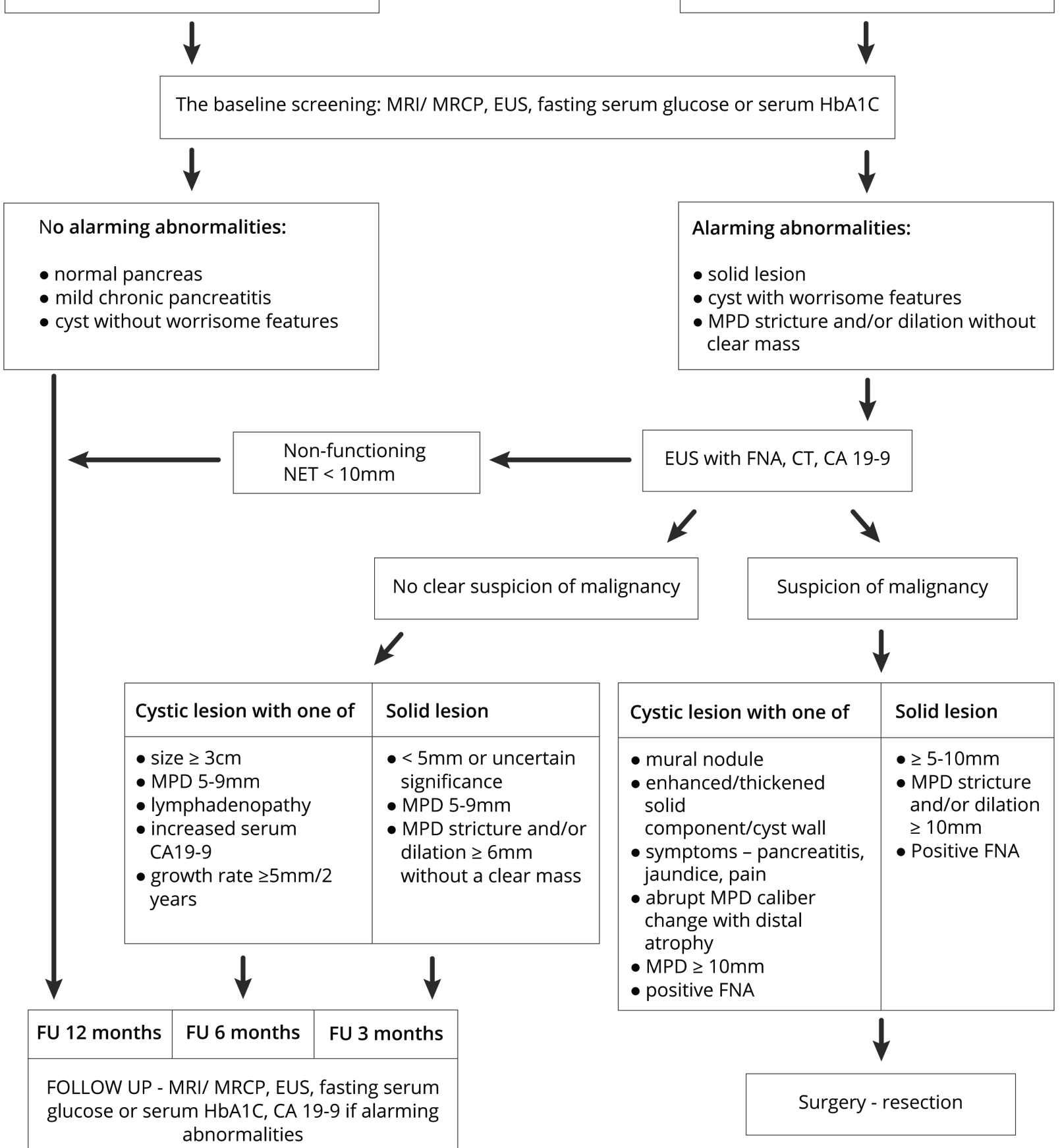

Figure 8. Flowchart of screening and follow-up of individuals in the increased risk of PC development (according to [18, 19] - created in collaboration with Service Center for E-Learning at Masaryk University, Faculty of Informatics). 
Age. The incidence of PC is increasing with age and it is typically a disease of the elderly. Ninety percent of newly diagnosed patients are over 55 years of age, with the majority over 70 [1].

Familial pancreatic cancer. Familial PC is defined as a family with at least 2 first-degree relatives affected by PC without other cancers or other known genetic syndromes or familial diseases. It is estimated that up to $10 \%$ of PC may have a familial component [18]. The number of first-and second-degree relatives with PC can be used to quantify PC risk. A family history of PC in one blood relative seems not to increase PC risk significantly, however, the risk of developing PC in relatives in families with 2 affected first-degree relatives is 6 to 18 -fold higher (lifetime risk $8 \%$ to $12 \%$ ) and kindreds with 3 affected first-degree relatives have a 32 to 57 -fold risk increase of developing PC (lifetime risk 40\%) [49].

Families with a member affected by $\mathrm{PC}$ at a younger age ( $<50$ years) bear a higher risk of PC development.

Hereditary pancreatic cancer syndromes. As mentioned earlier, certain germline mutations are known to significantly increase the risk of PC. They include BRCA2, p16, STK11/ LKB1, and PRSS1 mutations [19].

It has been shown that BRCA2 is present in $17 \%$ to $19 \%$ of families where at least 2 first-degree relatives have PC [18].

Patients with known Peutz-Jeghers syndrome represent a population with a very high risk in a wide range from 36 to 132 and a cumulative lifetime risk of $36 \%$ for the development of PC. Therefore, they may represent a group with the highest risk of PC and some sources recommend initiating the PC screening at the age of 30-35 in Peutz-Jeghers syndrome patients [19]. Hereditary pancreatitis is an autosomal dominant disease attributed mostly to the PRSS1 mutation. There is a high incidence of PC 30 to 40 years after the age of onset of recurrent attacks of pancreatitis. PC risk is 50-69 times higher, with an estimated lifetime risk of PC of $40 \%$ by 70 years of age [15]. The risk is doubled in smokers, who are diagnosed with PC on average 20 years earlier compared with nonsmoking hereditary pancreatitis individuals.

$\mathrm{PC}$ and chronic pancreatitis. Chronic pancreatitis (CP) is a progressive inflammation of the gland leading to irreversible morphological changes and an impairment of both the exocrine and later endocrine functions of the pancreas [50]. A higher risk of tumor growth in the context of chronic inflammation has been known for a long time and has been described in a number of neoplasms not only of the gastrointestinal tract. A similar relationship can be found in the case of CP and PC [24]. Patients with the sporadic form of CP have a risk of developing PC 10-20 times higher than people of the appropriate age without CP. The risk of developing pancreatic cancer during the life of a patient with a sporadic form of CP is $1.8 \%$ after 10 years and $4 \%$ after 20 years of disease duration $[49,51]$. Not all national guidelines consider an increase of PC risk in long-lasting, non-genetically related $\mathrm{CP}$ adequate for routine PC screening [52]. However, it is crucial to aggregate all present risk factors in each individual and also to conduct an adequate diagnostic in the event of the occurrence of new worrying symptoms in patients with $\mathrm{CP}$ (e.g. new-onset diabetes).

An exceptional group is the patients with a previously mentioned genetically determined hereditary form of chronic pancreatitis. These patients account for less than $1 \%$ of all CP cases. Hereditary CP is caused by a mutation in the cationic

Table 1. Risk factors of PC development (according to $[11,13,17,18]$ ).

\begin{tabular}{|c|c|c|}
\hline Increase in pancreatic cancer risk & Clinical risk factors & Genetic risk factors \\
\hline \multirow[t]{7}{*}{ Mild ( $<5$ times) } & BMI >30 (RR 1.2-1.5) & $\begin{array}{l}\text { Hereditary breast and ovarian cancer (HBOC) - BRCA1 } \\
\text { mutation (RR 1.9-5.3) }\end{array}$ \\
\hline & Diabetes mellitus (RR 1.4-2.2) & $\begin{array}{l}\text { Familial adenomatous polyposis (FAP)-APC mutation (RR } \\
4,46)\end{array}$ \\
\hline & Family history of 1 first degree relative with PC & $\begin{array}{l}\text { Hereditary nonpolyposis colorectal cancer (HNPCC)/Lynch } \\
\text { syndrome- } M S H 2, M L H 1 \text { etc. mutation (defective DNA mis- } \\
\text { match repair, microsatellite instability) (RR } 8.6-10.7 \text { ) }\end{array}$ \\
\hline & Smoking (RR 2-3.7) & $\begin{array}{l}\text { Hereditary breast and ovarian cancer (HBOC)-PALB2 muta- } \\
\text { tion }\end{array}$ \\
\hline & $\begin{array}{l}\text { Carcinogens exposure (polycyclic and chlorinated } \\
\text { hydrocarbons etc.) }\end{array}$ & Li-Fraumeni syndrome- $p 53$ mutation \\
\hline & High alcohol intake (RR 1.5) & Ataxia telangiectasia-ATM mutation (RR 2.7) \\
\hline & Helicobacter pylori infection (RR 1.5) & \\
\hline \multirow[t]{2}{*}{ Medium (5-10 times) } & Chronic pancreatitis & $\begin{array}{l}\text { Hereditary breast and ovarian cancer (HBOC)-BRCA2 muta- } \\
\text { tion (RR 5.9) }\end{array}$ \\
\hline & $\begin{array}{l}\text { Family history of } 2 \text { first degree relatives with PC } \\
\text { (RR 18) }\end{array}$ & Cystic fibrosis-CFTR mutation \\
\hline \multirow[t]{3}{*}{ High (>10 times) } & $\begin{array}{l}\text { Family history of } \geq 3 \text { relatives of any degree with PC } \\
\text { (RR 57) }\end{array}$ & $\begin{array}{l}\text { Familial atypical multiple mole melanoma (FAMMM) } \\
\text { syndrome-CDKN2A mutation (RR 16-46.6) }\end{array}$ \\
\hline & & Hereditary pancreatitis-PRSS-1 mutation (RR 50-69) \\
\hline & & Peutz-Jeghers syndrome-STK11 mutation (RR 36-132) \\
\hline
\end{tabular}


trypsinogen gene (PRSS 1) and is an autosomal dominant disease with penetration of up to $80 \%$. Characteristic of this disease are repeated attacks of acute pancreatitis with a high incidence of pancreatic tumor - approximately 50-80-fold increased risk of developing PC is present $[15,53]$.

The presence of chronic inflammation is associated with the production of free oxygen radicals, the production of cytokines, and increased production of pro-inflammatory transcription factors. Similar mediators of the inflammatory response pathways have been repeatedly demonstrated in $\mathrm{CP}$ and PC tissues. Nuclear factor kappa B (NF- $\mathrm{BB})$, cyclooxygenase 2 (COX-2), 5-lipoxygenase (5-LOX), interleukin-8 (IL-8), and other factors are involved in genetic damage, promote cell proliferation, inhibit apoptosis of the pancreatic cells and represent a link between chronic inflammation and tumor growth [51]. Pancreatic chronic inflammation appears to be an early step in the development of malignancy, with genetic alterations occurring as a result of prolonged inflammatory processes [54]. This may be evidenced, among other proofs, by the fact that PanIN lesions (representing individual steps of oncogenesis) are more common in patients with CP than in the general population [55].

In summary, $\mathrm{CP}$ is an established risk factor for PC because chronic inflammation promotes premalignant cell survival, autocrine stimulation of a protumorigenic environment, and desmoplasia. Progression of CP to PC occurrs over one to two decades in about $5 \%$ of $\mathrm{CP}$ patients, with relative risk of $\mathrm{PC}$ about 10 . The risk is much higher among patients with a hereditary predisposition. A substantial smoking history represents significant additional risk factor of PC development.

PC and smoking. Smoking is an independent risk factor not only for lung cancer, but also for cancer of the stomach, colon, and pancreas. According to the studies, smoking increases the risk of PC up to $2-3$ times, $10-15 \%$ (25\% by some sources) of cases of sporadic PC is expected to be conditioned by smoking [56-59]. The risk of developing PC is higher in people who smoke regularly for a long time (5 and more years) and is directly related to the number of cigarettes smoked per day (significantly with $>10$ cigarettes/ day). In smokers, PC is diagnosed at a younger age and more often within 1 year after the onset of the first symptoms, which may indicate a faster progression of PC in smokers [60]. Cigarette smoking is also an independent risk factor for the development of the alcoholic and idiopathic form of CP and is thought to accelerate disease progression by inducing chronic inflammation. Cigarette smoking is likely to be involved in carcinogenesis by activating the inflammatory response [61].

In those with family history and/or genetic predispositions for PC, smoking has even a greater effect (3.7-fold increased risk of developing $\mathrm{PC}$ ) and may present with the disease one to two decades earlier. In individuals with PRSS1 mutation, smoking increases the risk of PC by 2 -fold and decreases the age of PC onset by $10-20$ years, as noted above.
PC and diabetes mellitus. A relationship between PC and diabetes mellitus (DM) has been known for decades, but the exact etiological relationship has not been fully elucidated yet. Impaired glucose tolerance or DM is present in up to $80 \%$ of PC patients [62]. The risk of PC in DM is explained by the fact that increased insulin production by Langerhans islet beta cells leads both to the exhaustion of beta cells (diabetes itself), but also to a higher local concentration of growth and stimulant factors that contribute to the malignant transformation of the surrounding exocrine tissue. This idea is justified and there are studies that demonstrate a more frequent occurrence of PC in patients with a long history of DM with a relative risk of approximately 2 according to meta-analyzes from 2011 and 2017 [63, 64]. However, the increase in relative risk is probably lower than previously thought and even becomes statistically insignificant if we exclude patients in whom DM preceded the diagnosis of PC by a short period of time (2 to 3 years).

For this reason, we can define 2 subgroups of patients with co-occurring DM and PC. The first subgroup consists of patients in whom DM is a genetically and environmentally conditioned underlying disease and PC appears after a long history of DM (either with or without direct relationship). The second subgroup consists of patients with DM of short duration (2-3 years) before the diagnosis of PC. In most patients with $\mathrm{PC}$, the development of DM precedes the diagnosis of PC by $<2$ years, and the relative risk of a diagnosis of PC is 5.38 during the first year after diagnosis of DM [65]. Thus, we can speak of paraneoplastic DM, which is classified as a separate type of pancreatogenic diabetes (T3cDM) [66]. In this group of patients, DM may be the first manifestation of an otherwise asymptomatic malignancy, and DM is most likely a direct consequence of PC cells [63].

According to retrospective studies, PC will develop within 3 years of the diagnosis of DM in approximately $1 \%$ of diabetics, and given the total numbers, it is not possible to screen all newly diagnosed diabetics. Therefore, research today focuses mainly on identifying criteria that distinguish common DM from PC-related DM [62]. In the absence of a suitable biomarker, a number of authors have defined various distinguishing criteria between common DM and PC-related $\mathrm{DM}$, but these have been refuted by further research as insufficient, with no significant difference in the clinical picture of common DM and PC-related DM [67, 68]. In general, however, it can be assumed that targeted examination of elderly people with newly diagnosed, atypically manifesting DM may lead to improved detection of early stages of PC and thus to better therapeutic results [69].

Another important factor useful in stratifying the risk of developing PC could be the sex of patients. Our study showed a significantly higher prevalence of DM among women with PC (25\% of men vs. $43.9 \%$ of women, $\mathrm{p}=0.0008)$, while in the control group, DM was equally represented in both sexes (22.1\% in men vs. $17.2 \%$ in women, $\mathrm{p}=0.487$ ) [70]. 


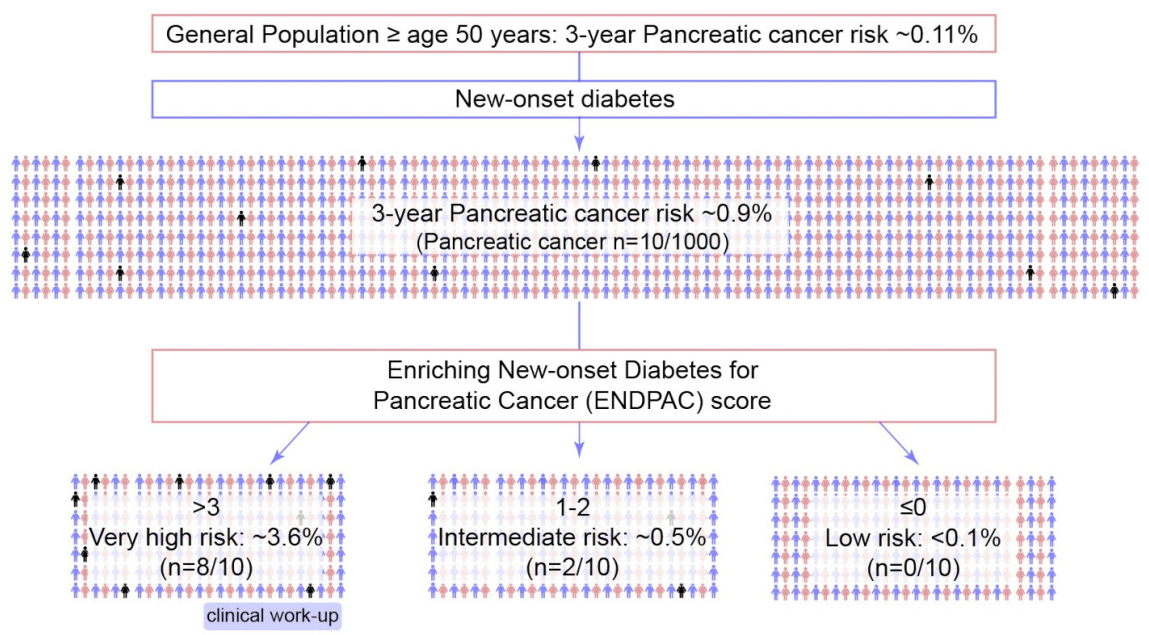

Modeling represents another alternative way to define a high-risk group among newly diagnosed diabetics without knowledge of a specific laboratory marker. By analyzing the documentation of more than 1,500 patients with newly diagnosed DM, the Mayo Clinic authors identified weight change, blood glucose fluctuations, and age as major risk factors, and developed their own Enriching New-onset Diabetes for Pancreatic Cancer (END-PAC) score capable of reliably identifying a group of patients at high risk of PC diagnosis over the next 3 years after the onset of DM $(80 \%$ sensitivity and specificity with a score $\geq 3$ ) [71]. The high negative predictive value at a score of 0 is significant when the risk of PC development is comparable to the general population. Overall, using the END-PAC scoring system, the authors achieved the definition of a population with about a $4 \%$ risk of PC development, which is considered the limit at which screening is effective (Figure 9).

Unfortunately, retrospective validation on a group of almost 14,000 patients did not reach conclusive results. PC occurred in only $2 \%$ of patients in the high-risk group defined by END-PAC within 3 years of the diagnosis of DM [72].

However, this is not the only similar attempt. The authors from the University of Pennsylvania evaluated the data from a cohort of more than 100,000 patients over the age of 35 with newly diagnosed DM. Over the next 3 years, PC was detected in $0.4 \%$ of them. Based on the data obtained, they created a prediction model including age, BMI, change in $\mathrm{BMI}$, smoking, PPI, anti-diabetic medication, and $\mathrm{HbA} 1 \mathrm{C}$ values, cholesterol, hemoglobin, creatinine, and ALP levels. With the necessity to examine $6.19 \%$ of newly diagnosed DM patients, they were able to identify PCs with $44.7 \%$ sensitivity and $94.0 \%$ specificity [73]. Further research and validation on large patient populations are needed to evaluate the applicability of these scoring systems.
In summary, long-lasting DM represents a factor increasing mildly the risk of PC while new-onset DM can be a paraneoplastic symptom. No simple strategy on how to differentiate common DM and PC-related DM has been discovered so far, however, several prediction models are being tested and research in the field of biomarkers is ongoing. At present, testing patients with newly diagnosed DM especially in presence of other PC risk factors (e.g. age, smoking, chronic pancreatitis) may lead to improved detection of early stages of PC and thus to better therapeutic results.

\section{Conclusion}

PC screening has not yet been introduced in today's clinical practice due to the absence of simple and effective methods. Thus, detecting the early stages of PC remains very problematic. Modern imaging methods are often expensive and invasive, so they remain reserved for groups of patients at high risk of developing PC. Research on laboratory markers has not yet revealed an indicator that would be able to identify patients with an early form of PC with sufficient sensitivity and specificity. However, this area of research is promising in the future and could lead to the desired results. Risk factors for PC are known and can be used to stratify the risk of PC. The selected group of patients with the highest level of risk must then be carefully monitored or grouped into registers (e.g. some genetic syndromes, cystic fibrosis, etc.). The use of risk factors for sporadic PC such as age, smoking, obesity, or chronic pancreatitis for a further selection of patients before imaging is problematic, as the incidence of PC in these groups is very low. However, individuals with an accumulation of risk factors may be in future potential candidates for PC screening. Also, the use of knowledge about the relationship between DM and PC can be very beneficial in the future after setting fixed criteria. 


\section{Future prospects}

Unfortunately, laboratory tests available today are not capable of reliable early diagnostics of PC but, in the future, we can expect rapid development of laboratory tests using the methods of proteomics, genomics, metabolomics, and so-called „liquid biopsy”. This may even allow population screening of PC in the general population.

In the field of imaging methods, an improvement is also necessary to enhance the detection of significant precursors or early PC but also to allow a better distinction from clinically nonsignificant lesions to avoid unnecessary surgery. The most sensitive and cost-effective imaging screening protocol still needs to be defined as well.

Prospective studies of the effect of surveillance programs on survival benefit, surgical morbidity, postoperative quality of life, and psychological stress are needed.

More research (e.g. large, prospective studies) on the role of PC risk factors and their interaction is necessary for precise identification of high-risk individuals.

Acknowledgements: This work was supported by the Ministry of Health, Czech Republic - conceptual development of research organisation (FNBr 65269705).

\section{References}

[1] SIEGEL RL, MILLER KD, JEMAL A. Cancer statistics, 2019. CA Cancer J Clin 2019; 69: 7-34.

[2] LOVECEK M, SKALICKY P, RYSKA M, GÜRLICH R, HLAVSA J et al. Current status regarding surgical treatment of pancreatic cancer in the Czech Republic. Rozhl Chir 2016; 95: 151-155.

[3] BASTURK O, HONG SM, WOOD LD, ADSAY NV, ALBORES-SAAVEDRA J et al. A Revised Classification System and Recommendations from the Baltimore Consensus Meeting for Neoplastic Precursor Lesions in the Pancreas. Am J Surg Pathol 2015; 39: 1730-41. https://doi.org/10.1097/ PAS.0000000000000533

[4] DISTLER M, AUST D, WEITZ J, PILARSKY C, GRÜTZMANN R. Precursor lesions for sporadic pancreatic cancer: PanIN, IPMN, and MCN. Biomed Res Int 2014; 2014: 474905. https://doi.org/10.1155/2014/474905

[5] BAZZICHETTO C, CONCIATORI F, LUCHINI C, SIMIONATO F, SANTORO R et al. From Genetic Alterations to Tumor Microenvironment: The Ariadne's String in Pancreatic Cancer. Cells 2020; 9: 309. https://doi.org/10.3390/ cells9020309

[6] YACHIDA S JONES S, BOZIC I ANTAL T, LEARY R et al. Distant Metastasis Occurs Late during the Genetic Evolution of Pancreatic Cancer. Nature 2010; 467: 1114-1117. https:// doi.org/10.1038/nature09515

[7] CAMPBELL PJ, YACHIDA S, MUDIE LJ, STEPHENS PJ, PLEASANCE ED et al. The patterns and dynamics of genomic instability in metastatic pancreatic cancer. Nature 2010; 467: 1109-1113. https://doi.org/10.1038/nature09460
[8] REAL FX, CIBRIÁN-UHALTE E, MARTINELLI P. Pancreatic Cancer Development and Progression: Remodeling the Model. Gastroenterology 2008; 135: 724-728. https://doi. org/10.1053/j.gastro.2008.07.033

[9] YU J, BLACKFORD AL, DAL MOLIN M, WOLFGANG CL, GOGGINS M. Time to Progression of Pancreatic Ductal Adenocarcinoma From Low-To-High Tumour Stages. Gut 2015; 64: 1783-1789. https://doi.org/10.1136/ gutjnl-2014-308653

[10] NOTTA F, CHAN-SENG-YUE M, LEMIRE M, LI Y, WILSON GW et al. A renewed model of pancreas cancer evolution based on genomic rearrangement patterns. Nature 2016; 538: 378-382. https://doi.org/10.1038/nature19823

[11] CHHODA A, LU L, CLERKIN BM, RISCH H, FARRELL JJ. Current Approaches to Pancreatic Cancer Screening. Am J Pathol 2019; 189: 22-35. https://doi.org/10.1016/j.ajpath.2018.09.013

[12] PARIKH R, MATHAI A, PARIKH S, SEKHAR GC, THOMAS R. Understanding and using sensitivity, specificity and predictive values. Indian J Ophthalmol 2008; 56: 45-50. https://doi.org/10.4103/0301-4738.37595

[13] MAISONNEUVE P, LOWENFELS AB. Risk factors for pancreatic cancer: a summary review of meta-analytical studies. Int J Epidemiol 2015; 44: 186-198. https://doi.org/10.1093/ ije/dyu 240

[14] SHARMA A, CHARI ST. Pancreatic cancer and diabetes mellitus. Curr Treat Opinions Gastroenterol 2018; 16: 466478. https://doi.org/10.1007/s11938-018-0197-8

[15] TEICH N, MOSSNER J. Hereditary chronic pancreatitis. Best Pract Res Clin Gastroenterol 2008; 22: 115-130. https:// doi.org/10.1016/j.bpg.2007.10.019

[16] LI D, XIE K, WOLFF R, ABBRUZZESE JL. Pancreatic cancer. Lancet 2004; 363: 1049-1057. https://doi.org/10.1016/ S0140-6736(04)15841-8

[17] PORUK KE, FIRPO MA, ADLER DG. Screening for Pancreatic Cancer: Why, How, and Who? Ann Surg 2013; 257: 17-26. https://doi.org/10.1097/SLA.0b013e31825ffbfb

[18] KLAPMAN J, MALAFA MP. Early detection of pancreatic cancer: whz, who and how to screen. Cancer Control 2008; 15: 280-287. https://doi.org/10.1177/107327480801500402

[19] GOGGINS M, OVERBEEK KA, BRAND R, SYNGAL S, DEL CHIARO $\mathrm{M}$ et al. Management of patients with increased risk for familial pancreatic cancer: updated recommendations from the International Cancer of the Pancreas Screening (CAPS) Consortium. Gut 2020; 69:7-17. https:// doi.org/10.1136/gutjnl-2019-319352

[20] BORECKA M, ZEMANKOVA P, VOCKA M, SOUCEK $\mathrm{P}$, SOUKUPOVA $\mathrm{J}$ et al. Mutation analysis of the PALB2 gene in unselected pancreatic cancer patients in the Czech Republic. Cancer Genet 2016; 209: 199-204. https://doi. org/10.1016/j.cancergen.2016.03.003

[21] BENZEL J, FENDRICH V. Familial Pancreatic Cancer. Oncol Res Treat 2018; 41: 611-618. https://doi. org/10.1159/000493473

[22] DİTĚ P, HERMANOVÁ M, TRNA J, NOVOTNÝ I, RŮŽIČKA $M$ et al. The role of chronic inflammation: chronic pancreatitis as a risk factor of pancreatic cancer. Dig Dis 2012; 30: 277-283. https://doi.org/10.1159/000336991 
[23] GUO Y, LIU W, WU J. Helicobacter pylori infection and pancreatic cancer risk: A meta-analysis. J Cancer Res Ther 2016; 12: C229-C232. https://doi.org/10.4103/0973-1482.200744

[24] SCHULTE A, PANDEYA N, FAWCETT J, FRITSCHI L, RISCH HA et al. Association between Helicobacter pylori and pancreatic cancer risk: a meta-analysis. Cancer Causes Control 2015; 26: 1027-1035. https://doi.org/10.1007/ s10552-015-0595-3

[25] CANTO MI, ALMARIO JA, SCHULICK RD, YEO CJ, KLEIN A et al. Risk of Neoplastic Progression in Individuals at High Risk for Pancreatic Cancer Undergoing Longterm Surveillance. Gastroenterology 2018; 155: 740-751.e2. https://doi.org/10.1053/j.gastro.2018.05.035

[26] CORRAL JE, MARETH KF, RIEGERT-JOHNSON DL, DAS A, WALLACE MB. Diagnostic Yield from Screening Asymptomatic Individuals at High Risk for Pancreatic Cancer: A Meta-analysis of Cohort Studies. Clin Gastroenterol Hepatol 2019; 17: 41-53. https://doi.org/10.1016/j.cgh.2018.04.065

[27] LEE ES, LEE JM. Imaging diagnosis of pancreatic cancer: a state-of-the-art review. World J Gastroenterol 2014; 20: 7864-7877. https://doi.org/10.3748/wjg.v20.i24.7864

[28] YOUSAF MN, CHAUDHARY FS, EHSAN A, SUAREZ AL, MUNIRAJ T et al. Endoscopic ultrasound (EUS) and the management of pancreatic cancer. BMJ Open Gastroenterol 2020; 7: e000408. https://doi.org/10.1136/bmjgast-2020-000408

[29] DALLONGEVILLE A, CORNO L, SILVERA S, BOULAYCOLETTA I, ZINS M. Initial Diagnosis and Staging of Pancreatic Cancer Including Main Differentials. Semin Ultrasound CT MR 2019; 40: 436-468. https://doi.org/10.1053/j. sult.2019.08.001

[30] CHEN FM, NI JM, ZHANG ZY, ZHANG L, LI B et al. Presurgical Evaluation of Pancreatic Cancer: A Comprehensive Imaging Comparison of CT Versus MRI. AJR Am J Roentgenol 2016; 206: 526-535. https://doi.org/10.2214/ AJR.15.15236

[31] YEH R, DERCLE L, GARG I, WANG ZJ, HOUGH DM et al. The Role of 18F-FDG PET/CT and PET/MRI in Pancreatic Ductal Adenocarcinoma. Abdom Radiol (NY) 2018; 43: 415-434. https://doi.org/10.1007/s00261-017-1374-2

[32] DUCREUX M, CUHNA AS, CARAMELLA C, HOLLEBECQUE A, BURTIN P et al. Cancer of the pancreas: ESMO Clinical Practice Guidelines for diagnosis, treatment and follow-up. Ann Oncol 2015; 26 Suppl 5: v56-68. https://doi. org/10.1093/annonc/mdv295

[33] CORRAL JE, DAS A, BRUNO MJ, WALLACE MB. Costeffectiveness of pancreatic cancer surveillance in highrisk individuals. Pancreas 2019; 48: 526-536. https://doi. org/10.1097/MPA.0000000000001268

[34] HUMPHRIS JL, CHANG DK, JOHNS AL, SCARLETT CJ, PAJIC $\mathrm{M}$ et al. The prognostic and predictive value of serum CA 19.9 in pancreatic cancer. Ann Oncol 2012; 23: 17131722. https://doi.org/10.1093/annonc/mdr561

[35] KAU SY, SHYR YM, SU CH, WU CW, LUI WY. Diagnostic and prognostic values of CA 19-9 and CEA in periampullary cancers. J Am Coll Surg 1999; 188: 415-420. https://doi. org/10.1016/s1072-7515(98)00326-3
[36] LOCKER GY, HAMILTON S, HARRIS J, JESSUP JM, KEMENY N et al. ASCO 2006 update of recommendations for the use of tumor markers in gastrointestinal cancer. J Clin Oncol 2006; 24: 5313-5327. https://doi.org/10.1200/ JCO.2006.08.2644

[37] ZEMANEK T, MELICHAR B, LOVECEK M, SOUCEK P, MOHELNIKOVA-DUCHONOVA B. Biomarkers and Pathways of Chemoresistance and Chemosensitivity for Personalized Treatment of Pancreatic Adenocarcinoma. Pharmacogenomics 2019; 20: 113-127. https://doi.org/10.2217/ pgs-2018-0073

[38] YUE T, MAUPIN KA, FALLON B, LI L, PARTYKA K et al. Enhanced discrimination of malignant from benign pancreatic disease by measuring the CA 19-9 antigen on specific protein carriers. PLoS One 2011; 6: e29180. https://doi. org/10.1371/journal.pone.0029180

[39] RITCHIE SA, CHITOU B, ZHENG Q JAYASINGHE D, JIN W et al. Pancreatic cancer serum biomarker PC-594: Diagnostic performance and comparison to CA 19-9. World J Gastroenterol 2015; 21: 6604-6612. https://doi.org/10.3748/ wjg.v21.i21.6604

[40] DİTĚ P, NOVOTNÝ I, DVOŘÁČKOVÁ J, KIANIČKA B, BLAHO M et al. Pancreatic Solid Focal Lesions: Differential Diagnosis between Autoimmune Pancreatitis and Pancreatic Cancer. Dig Dis 2019; 37: 416-421. https://doi. org/10.1159/000499762

[41] KUNOVSKÝ L, TESAŘÍKOVÁ P, KALA Z, KROUPA R, KYSELA P et al. The Use of Biomarkers in Early Diagnostics of Pancreatic Cancer. Can J Gastroenterol Hepatol 2018; 2018: 5389820. https://doi.org/10.1155/2018/5389820

[42] KAMYABI N, BERNARD V, MAITRA A. Liquid Biopsies in Pancreatic Cancer. Expert Rev Anticancer Ther 2019; 19: 869-878. https://doi.org/10.1080/14737140.2019.1670063

[43] NAGAI M, SHO M, AKAHORI T, NAKAGAWA K, NAKAMURA K. Application of Liquid Biopsy for Surgical Management of Pancreatic Cancer. Ann Gastroenterol Surg 2020; 4: 216-223. https://doi.org/10.1002/ags3.12317

[44] JENKINSON C, ELLIOTT VL, EVANS A, OLDFIELD L, JENKINS RE et al. Decreased Serum Thrombospondin-1 Levels in Pancreatic Cancer Patients up to 24 Months Prior to Clinical Diagnosis: Association With Diabetes Mellitus. Clin Cancer Res 2016; 22: 1734-1743. https://doi. org/10.1158/1078-0432.CCR-15-0879

[45] KIM J, BAMLET WR, OBERG AL, CHAFFEE KG, DONAHUE G et al. Detection of Early Pancreatic Ductal Adenocarcinoma With thrombospondin-2 and CA19-9 Blood Markers. Sci Transl Med 2017; 9: eaaf9655. https://doi. org/10.1126/scitranslmed.aah5583

[46] BALASENTHIL S, HUANG Y, LIU S, MARSH T, CHEN J et al. A Plasma Biomarker Panel to Identify Surgically Resectable Early-Stage Pancreatic Cancer. J Natl Cancer Inst 2017; 109: djw341. https://doi.org/10.1093/jnci/djw341

[47] GALL TMH, BELETE S, KHANDERIA E, FRAMPTON AE, JIAO LR. Circulating Tumor Cells and Cell-Free DNA in Pancreatic Ductal Adenocarcinoma. Am J Pathol 2019; 189: 71-81. https://doi.org/10.1016/j.ajpath.2018.03.020 
[48] WINTER K, TALAR-WOJNAROWSKA R, DABROWSKI A, DEGOWSKA M, DURLIK M et al. Diagnostic and therapeutic recommendations in pancreatic ductal adenocarcinoma. Recommendations of the Working Group of the Polish Pancreatic Club. Prz Gastroenterol 2019; 14: 1-18. https:// doi.org/10.5114/pg.2019.83422

[49] MALKA D, HAMMEL P, MAIRE F, RUFAT P, MADEIRA I et al. Risk of Pancreatic Adenocarcinoma in Chronic Pancreatitis. Gut 2002; 51: 849-852. https://doi.org/10.1136/ gut.51.6.849

[50] SHIMOSEGAWA T. A New Insight into Chronic Pancreatitis. Tohoku J Exp Med 2019; 248: 225-238. https://doi. org/10.1620/tjem.248.225

[51] GARCEA G, DENNISON AR, STEWARD WP, BERRY DP. Role of inflammation in pancreatic carcinogenesis and the implications for future therapy. Pancreatology 2005; 5: 514529. https://doi.org/10.1159/000087493

[52] KADAJ-LIPKA R, LIPIŃSKI M, ADRYCH K, DURLIK M, GASIOROWSKA A et al. Diagnostic and therapeutic recommendations for chronic pancreatitis. Recommendations of the Working Group of the Polish Society of Gastroenterology and the Polish Pancreas Club. Prz Gastroenterol 2018; 13: 167-181. https://doi.org/10.5114/pg.2018.78067

[53] ULRICH CD 2ND, KOPRAS E, WU Y, WARD S. Hereditary Pancreatitis: Epidemiology, Molecules, Mutations, and Models. J Lab Clin Med 2000; 136: 260-274. https://doi. org/10.1067/mlc.2000.109405

[54] FARROW B, EVERS BM. Inflammation and the development of pancreatic cancer. Surg Oncol 2002; 10: 153-169. https://doi.org/10.1016/s0960-7404(02)00015-4

[55] HWANG IK, KIM H, LEE YS, KIM J, CHO JY et al. Presence of Pancreatic Intraepithelial neoplasia-3 in a Background of Chronic Pancreatitis in Pancreatic Cancer Patients. Cancer Sci 2015; 106: 1408-1413. https://doi.org/10.1111/cas.12744

[56] MAISONNEUVE P, LOWENFELS AB. Epidemiology of pancreatic cancer: an update. Dig Dis 2010; 28: 645-656. https://doi.org/10.1159/000320068

[57] VRIELING A, BUENO-DE-MESQUITA HB, BOSHUIZEN HC, MICHAUD DS, SEVERINSEN MT et al. Cigarette smoking, environmental tobacco smoke exposure and pancreatic cancer risk in the European Prospective Investigation into Cancer and Nutrition. Int J Cancer 2010; 126: 2394-2403. https://doi.org/10.1002/ijc. 24907

[58] KOYANAGI YN, ITO H, MATSUO K, SUGAWARA Y, HIDAKA A et al. Smoking and Pancreatic Cancer Incidence: A Pooled Analysis of 10 Population-Based Cohort Studies in Japan. Cancer Epidemiol Biomarkers Prev 2019; 28: 13701378. https://doi.org/10.1158/1055-9965.EPI-18-1327

[59] VILLENEUVE PJ, JOHNSON KC, HANLEY AJG, MAO Y. Alcohol, Tobacco and Coffee Consumption and the Risk of Pancreatic Cancer: Results from the Canadian Enhanced Surveillance System Case-Control Project. Canadian Registries Epidemiology Research Group. Eur J Cancer Prev 2000; 9: 49-58. https://doi.org/10.1097/00008469-20000200000007

[60] DÍTĚ P, TRNA J, BĚLOBRÁDKOVÁ J, NOVOTNÝ I, HERMANOVÁ $M$ et al. Pancreatic cancer--association with diabetes mellitus and smoking. Vnitr Lek 2011; 57: 159-162.
[61] MALFERTHEINER P, SCHUTTE K. Smoking - a trigger for chronic inflammation and cancer development in the pancreas. Am J Gastroenterol 2006; 101: 160-162. https:// doi.org/10.1111/j.1572-0241.2006.00402.x

[62] CHARI ST, LEIBSON CL, RABE KG, RANSOM J, DE ANDRADE $M$ et al. Probability of pancreatic cancer following diabetes: A population-based study. Gastroenterology 2005; 129: 504-511. https://doi.org/10.1016/j.gastro.2005.05.007

[63] BEN Q, XU M, NING X, LIU J, HONG S et al. Diabetes mellitus and risk of pancreatic cancer: A meta-analysis of cohort studies. Eur J Cancer 2011; 47: 1928-1937. https://doi. org/10.1016/j.ejca.2011.03.003

[64] TAN J, YOU Y, GUO F, XU J, DAI H et al. Association of elevated risk of pancreatic cancer in diabetic patients: A systematic review and meta-analysis. Oncol Lett 2017; 13: 1247-1255. https://doi.org/10.3892/ol.2017.5586

[65] CHARI ST, LEIBSON CL, RABE KG, TIMMONS LJ, RANSOM J et al. Pancreatic cancer-associated diabetes mellitus: prevalence and temporal association with diagnosis of cancer. Gastroenterology 2008; 134: 95-101. https://doi. org/10.1053/j.gastro.2007.10.040

[66] ANDERSEN DK, KORC M, PETERSEN GM, EIBL G, LI D et al. Diabetes, Pancreatogenic Diabetes, and Pancreatic Cancer. Diabetes 2017; 66: 1103-1110. https://doi.org/10.2337/ db16-1477

[67] NOY A, BILEZIKIAN JP. Clinical review 63: Diabetes and pancreatic cancer: clues to the early diagnosis of pancreatic malignancy. J Clin Endocrinol Metab 1994; 79: 1223-1231. https://doi.org/10.1210/jcem.79.5.7962312

[68] PANNALA R, LEIRNESS JB, BAMLET WR, BASU A, PETERSEN GM et al. Prevalence and clinical profile of pancreatic cancer-associated diabetes mellitus. Gastroenterology 2008; 134: 981-987. https://doi.org/10.1053/j.gastro.2008.01.039

[69] DAMIANO J, BORDIER L, LE BERRE JP, MARGERY J, DUPUY $\mathrm{O}$ et al. Should pancreas imaging be recommended in patients over 50 years when diabetes is discovered because of acute symptoms? Diabet Metab 2004; 30: 203-207. https:// doi.org/10.1016/s1262-3636(07)70111-8

[70] TRNA J, DÍTĚ P, ADAMCOVÁ A, CRAWFORD BJ, HERMANOVÁ M. Diabetes mellitus in pancreatic cancer patients in the Czech Republic: sex differences. Exp Diabetes Res 2012; 2012: 414893. https://doi.org/10.1155/2012/414893

[71] SHARMA A, KANDLAKUNTA H, NAGPAL SJS, FENG $\mathrm{Z}, \mathrm{HOOS} \mathrm{W}$ et al. Model to Determine Risk of Pancreatic Cancer in Patients with New-Onset Diabetes. Gastroenterology 2018; 155: 730-739. https://doi.org/10.1053/j.gastro.2018.05.023

[72] CHEN W, BUTLER RK, LUSTIGOVA E, CHARI ST, WU BU. Validation of the Enriching New-Onset Diabetes for Pancreatic Cancer Model in a Diverse and Integrated Healthcare Setting. Dig Dis Sci 2020. https://doi.org/10.1007/ s10620-020-06139-z

[73] BOURSI B, FINKELMAN B, GIANTONIO BJ, HAYNES K, RUSTGI AK et al. A Clinical Prediction Model to Assess Risk for Pancreatic Cancer Among Patients With New-Onset Diabetes. Gastroenterology 2017; 152: 840-850. e3. https:// doi.org/10.1053/j.gastro.2016.11.046 